he is obviously unfitted for his post, and the sooner his services are dispensed with the better.

Although I can quite understand that much difficulty may arise in efficiently carrying out an examination in operative surgery when an extremely large number of candidates have to be tested, I cannot think that it is insuperable, and it is only if it were so considered that would at all justify the question being raised as to whether it is desirable that the test should be enforced. Having regard to the importance of operative surgery, which has made such giant strides of late years, the abolition of the test at the examinations for surgical licences would, in my opinion, be calamitous to the best interests of surgical education. It is stated that the dearth of subjects is one great difficulty, and that their ntilisation for this purpose may injuriously affect the teaching and study of practical anatony. Assuming, however, that between 500 and 600 candidates presented themselves annually for the final examinations of the Conjoint Board in London-and that is probably a large estinuate,-I would say, from my experience as an examiner, that for such a number twenty-four subjects would probably be found quite sufficient; and having regard to the facilities with which they can now be procured, there could hardly be much difficulty, in a city with such an exceptionally large population as London has, in getting the required number, or even a much larger one if necessary. Then I understand that the time required to conduct this part of the examination is found to be a source of trouble and difficulty to some of the examiners who are believed to be favourable to the abolition of the test. If this be the case, I would suggest one of two coursesviz., either the appointment of other but equally efficient examiners who perhaps may have more leisure at their disposal, or of assistant supplemental examiners. That it is desirable there should be a practical test in this branch of our art is a proposition which, I think, hardly admits of discussion. Examinations are, as Professor Humphry has said, "the despots of education"; and we may reasonably anticipate that the abolition of the test would be promptly followed by the cessation of systematic teaching of operative surgery, and any surgical curriculum without this would, in my opinion, be distinctly defective. I regard it as one of the most important branches of surgical education, as it gives opportunity not only for the development of manual dexterity in operating, but also for the study of the surgical indications for its many and various applications.

I have known of more than one instance in which a surgeon, a few days after obtaining his surgical qualification, was called upon and required to perform operations of the most serious kind, and without having the advantage of any skilled assistant. In these cases, if the manipulative skill and knowledge derived from the study of operative surgery had been wanting, the results would, in all probability, have been very disastrous. There is one point which I think should never be lost sight of, and that is the desirability of candidates being tested for the most part on operations of emergency. In this opinion my friend $\mathrm{Mr}$ Teale, I know, coincides. It is satisfactory to note that in the recent debate on this subject in the General Medical Council, not only did $\mathrm{Mr}$. Teale express himself strongly as regards the importance of the operative surgery test, but had coinciding with him surgeons of such erninence as Sir J. Simon, Sir George Macleod, and Professors Humphry, R. Macnamara, and C. Heath.

I am, Sirs, yours faithfully,

$$
\text { WILLIAM STOKES, }
$$

Professor of Surgery, Royal College of Surgeons, Ireland. Merrion-square, Dublin, Dec. 10th, 1888.

\section{MENSTRUATION AND THE OVARIES.}

\section{To the Editors of THE LANCET.}

SIRs,-It is perfectly true that Dr. Aveling was the first to use the word "nidation"; but, whilst we are grateful to him for the invention of this most convenient term, we are not now inclined to follow him in the useless purpose to which he puts it. The very fact that Dr. Aveling uses the phrase "meaningless and unscientific Fallopian theory" conclusively proves, what is the fact, that he has not in the least understood my letter, and therefore I need not discuss the matter further with him. Dr. Harry Campbell, on the contrary, clearly observes the point at issue, and believes, in connexion with it-and I agree with him entirely, - that ovulation in all probability is a necessary part of the menstrual rhythm. The only point upon which we differ is that he desires to retain the belief that ovulation and menstruation are concurrent and coincident. If this were so, we should have, in either post-mortem or ante-mortem examination of the ovaries, a definite number of ripe, ripening, and decadent follicles proportionate to the methodical order of the performance of menstruation. But everyone knows that it is not so. In a statistical account of all the arailable information which my operations have enabled me to tabulate, and published in the Medical Times and Gazette and in the Gynocological Journal, it is clearly shown that the proportion of ripe ova to menstrual periods does not give more than two or three ripe ova in a year. It is, therefore, for Dr. Harry Campbell, who believes that ovulation and menstruation are coincident, to advance a single fact or observation which will support his view. It is not sufficient merely to reiterate what has been handed down from generation to generation without proof when the statement is challenged, and it is this traditional belie in the concurrence and coincidence of menstruation and ovulation which is at the bottom of all the fallacies of the physiology and pathology of the ovaries.

De Sinety and Melassez, and numerous other observers, haveshown thatovulation is going on during the whole of life; menstruation occurs only over a limited part of it. There is one crux which faces the supporters of the ovular theories, but they have passed it by (as Dr. Aveling has done) with out a word. Another fact quite as conclusive is that menstruation is never interfered with by any disease of the ovaries; whereas disease of the tubes and uterus (and not mere occlusion, but any disease of the tubes, or almost any disease of the uterus) will alter menstruation, may increase or diminish it, may convert it into continuous metrorrhagia, or cause it entirely to disappear. This is perfectly paralle with all the facts known to us about the influence of disease upon function. If the kidneys are diseased, they influence the function of the secretion of urine, because they are its immeliate agency. If ovulation be the cause of menstruation, or the ovaries be its immediate agency, then disease of these organs should show distinct evidence of their power. Removal of one should diminish it by half, unless the remaining ovary gets hypertrophied; and removal of both should entirely suppress the function. But no such results are obtained. We are further asked to believe that the retention of a microscopical fragment of one organ will lead to the maintenance of the complete physiolorica function attributed to two in their entirety. It is like asking us to believe that a man could pass fifty ounces of healthy urine from a remainder of one kidney, say, weighing ten grains-an assumption too absurd for further discussion.

I am, Sirs, your obedient servant,

Birmingham, Dec. 1st, 1888 . LAWSON TAIT.

\section{"THE BRITISH EMIGRATION SERVICE." To the Editors of THE LANCET.}

SIRs,-I observe in THE LANCET of Nov. 24th last 2 report by your Special Commissioner on the British emigration service. In that report he refers to an emigrant depót, and remarlss that the waste-pipes from the fixed washing. stands there communicated directly with the drains, afterwards qualifying this by saying that there was no trap visible. I would like, in justice to our watchfulness and strict supervision of all those places, to inform you that the whole system has been thoroughly smoke-tested lately by the officers of this department, and no trace of smoke was discoverable on the prenises. As a matter of fact, all the washing-stands referred to are trapped, and easily accessible by removing a portion of the woodwork. The other two w.c.'s, situated in the centre of the building, have two small hinged windows opening into the staircase. 'I'hey' are not any darker than such closets generally are when they are situated near the centre of a building or dwelling house, as unfortunately too many of them are. I would like to point out to your commissioner that erery closet situated witlin a dwelling house is ventilated througl the dwelling house, and not the dwelling house through it, unless special mechanical apparatus be emplored to cause an up current, which of course, as you are aware, no one has power to enforce. Such a question as this presents " no difficulty in enforcing," as suggested by your reporter. 
The difficulty is that there is no law about it at all. The question of fresh effluvia emanating from a w.c. into a dwelling house and contaminating the air of it, to the injury of health, is a matter on which doctors widely differ, as they sometimes do on more vital questions.

I am, Sirs, yours faithfully,

PeTER Fyfe,

Sanitary Department, Glasgow, Dec. 5th, 1888. Sanitary Inspector.

THE NEW WAY OF RAISING THE EPIGLOTTIS ETC. BY UTMOST MANUAL EXTENSION OF HEAD AND NECK, AND THE RECENT ADJOURNED DISCUSSION.

To the Editors of THE LANCET.

SIRS,-In the accurate report in THE LANCET of the 24th ult. of the recent adjourned discussion at the Medical Society of London appears an apology from me made under false impressions, and which is so inconsistent with the title of my paper, "On a new and only way of Raising the Epiglottis," that I must beg a short space in yonr valuable columins for a correction.

On reference to the report of the adjourned discussion, it will be seen that, although Mr. T. C. Bryant, of Guy's Hospital, who had been kind enough to watch some of my work at the time, said " the facts submitted were supported by demonstrations upon the 'dead body" and that "he was quite prepared to endorse Dr. Howard's remarks, or most of them "; while Sir William Mac Cormac related a recent case of his own exactly corroborating these facts; though Mr. Lennox Browne related an experience which "supported Dr. Howard's contention "; while Mr. Knowsley Thornton said, "Dr. Howard had a perfect right to speak of his way as a new method;" and though during the entire discussion not a single point as to the facts or their alleged purport was for a moment in dispute;-notwithstanding all this, in the body of my closing remarks will be found a very complete apology from me for having apparently overlooked the claims of a prior or contemporaneous worker on similar lines, and robbed him of the credit due to him. This apology was elicited by a surprise, and was given without reflection, in consequence of an impressive speech to that effect generously made by Mr. Knowsley Thornton on behalf of a friend who had been notified of the coming discussion, but was absent. The complaint in question was based upon a "paper" in the Edinburgh Medical Journal $-a$ proposed instrument in that connexion-and a case. On an examination since, I find not one of these things mentioned in the index of the journal in question, and that no such "paper" or abstract of such a "paper" is there published. As regards the case, it seems to have been reported specially to illustrate the relative superiority of my own method of artificial respiration, which, in contrast to Silvester's in another case mentioned, seems to have been employed with striking success on that occasion.

These events do not date back ten years ago as stated. The quotations made in support of supposed claims were, I find, made correctly, not from a "paper," however, but from remarts made at meetings on May 5th and on July 7th respectively in 1880 . The case-the experience in which seems to have been the source of whatever followed at subsequent meetings-was described in the course of a discussion some months before, or on March 5th, 1880. On that the earliest occasion or event referred to by Mr. Thornton's friend, he is reported in the Edinburgh Medical Journal to have said: "He had the greatest faith in Howard's method, and related this case to show how efficient it is in urgent cases of asphyxia, however produced." A recognition of the value of head and neck extension long ago by Mr. Thornton's friend seems correct, for, in accordance with my old directions for passive extension, he said: "Two pillows were placed under the shoulders, and the head allowed to fall l well back, when "the air rushed into the chest in a manner delightful to observe." Further "He mentioned this case to show the great value of a particular method of artificial respiration in a case of greatest urgency, where, as in this case, e.g., the patient could not be moved," for "he had no hesitation in saying that Howard's method saved the patient's life." I by no means wish to be understood as making a complaint myself, but as I privately promised Mr. Thornton I would make even further public correction as the facts on examina- tion might seem to allow, I cannot excuse myself from doing so, simply because the nature of the correction is so very different from what I was so ready to think it would have to be. Between these facts and what $I$ was led for the moment to suppose them to be the discrepancy is unfortunately great and amazing. In view of the facts, my apology is so absurdly contradictory and misleading, I have no choice but to retract it.

I hope I shall be excused for having recalled some of the forgotten statements made at the time in the account of the above case, the report of which was both new and interesting to me, and for the results in which Mr. Thornton's friend, as well as myself, cannot, I am sure, but feel grateful. I am, Sirs, yours faithfully,

London, Dec. 6th, 1888.

BENJAMIN HowaRD.

\section{SIR MORELL MACKENZIE AND THE ROYAT}

\section{COLLEGE OF PHYSICIANS OF LONDON.}

THE Registrar presents his compliments to the Editors of THE LANCET, and will feel obliged by their insertion in the next issue of the journal of the following letter which appeared in The Times of the 12 th inst. (to-day):-

\section{To the Editor of The Times.}

Sir,-The following paragraph appeared in the second edition of the Pall Mall Gavette of the 8th inst. :-

"George Fitz-James Darker, M.D., F.R.C.S., of St. Thomas's Hospital, who was present at the conclave at, the College of Physicians when the decree to boycott Sir Morell Mackenzie was drawn up, writes as follows: 'At that meeting I (in company with five or six others) protested against the decision arrived at-namely, to advise our colleagues in Edinburgh not to recognise Sir M. Mackenzie's visit to that city. I consider this boycotting of an eminent medical man a mean and cowardly action, and unworthy of the profession to which I have the honour to belong."

The answer to this statement is full and conclusive. 1. No question relating to Sir Morell Mackenzie has been discussed by the College of Physicians. 2. No meeting of the College has taken place since Oct. 25th last. 3. No communications have passed between this College and any other corporate body or persons on the subject. 4. Dr. Darker is quite unknown to the College, and could not have been present at any meeting whatever of that body, had such taken place; moreover, his name does not appear on the Medical Register.

There is, therefore, no foundation whatever for the paragraph quoted, which appears to have been designed for some other purpose than the furtherance of justice and truth. I am, Sir, your obedient servant,

Henry A. Pitman, Registrar.

Royal College of Physicians, London, S.W., Dec. 11th.

\section{LIVERPOOL.}

(From our own Correspondent.)

THE PREVENTION OF CRUELTY TO CHILDREN.

Mr. Justice WILLs, in charging the Grand Jury at the Assizes now sitting here, referred to the valuable assistance afforded by the Society for the Prevention of Cruelty to Children in taking up cases where there appeared to be gross parental neglect. Although the Society has been in existence some years and its formation was followed by that of a similar society in London, the learned judge stated that he liad never heard of it before. The Society acts in a double capacity, not only as public prosecutors in cases where cruelty by commission or omission has been proved, but also in deterring others from committing similar offences.

\section{TYPHOID FEVER AT ST. HELENS.}

For some time past there has been a severe epidemic of typhoid fever at St. Helens, several leading inhabitants having fallen victims to it, while others who have been infected are happily recovering. Dr. Garton, who has been in attendance on some of the patients, was himself taken ill, but this appears to have been from overwork.

$$
\text { DEATH OF THE MAYOR OF BIRKENHEAD. }
$$

Within a month of being elected to the office of Mayor of Birkenhead, Mr. FrederickSmith, alderman of that borough, 